\title{
EDITORIAL
}

(cc) BY-NC

\section{Schneider's first-rank symptoms and treatment outcome}

\author{
Raffael Massuda iD \\ Departamento de Psiquiatria, Universidade Federal do Paraná (UFPR), Curitiba, PR, Brazil.
}

The diagnosis of schizophrenia and its differentiation from other disorders with psychotic symptoms has always been challenging in the field of psychiatry. Historically, the concept of schizophrenia spectrum disorder, as well as its symptoms and diagnostic criteria, were described by several authors in the 19th and 20th centuries, including Benedict-Augustin Morel, Emil Kraepelin, Paul Eugen Bleuler, and Kurt Schneider. Schneider's conceptualization of first-rank symptoms (FRS) was a particularly important contribution to the diagnosis of schizophrenia. ${ }^{1}$

Schneider's FRS were intended to differentiate schizophrenia reliably from other psychotic disorders. For this purpose, he qualitatively organized symptoms as firstor second-rank. Schneider's description influenced the Research Diagnostic Criteria, ICD-10, DSM-III, and DSMIV. ${ }^{2}$ Although FRS were excluded in the DSM-5 Criterion A for schizophrenia, they directly impacted diagnostic practice for decades. ${ }^{2,3}$

In a Cochrane review of diagnostic accuracy published in 2015 , FRS had a sensitivity of $57 \%(50.4$ to $63.3 \%)$ and a specificity of $81.4 \%$ (74 to $87.1 \%$ ) for differentiation of schizophrenia from other psychiatric disorders. ${ }^{4}$ Despite several methodological issues in the included studies, this systematic review shows that assessment of FRS in patients could indeed help clinicians to diagnose schizophrenia. $^{3}$

In this context, the present issue of the Brazilian Journal of Psychiatry includes an interesting article published by Malinowski et al. that relates psychopathology with treatment outcomes. Their study shows that the absence of specific FRS - arguing voices, voices commenting on one's actions, and thought broadcasting in patients having their first psychotic episode is related to remission after 2 months of risperidone therapy. ${ }^{5}$
It is worth mentioning that only $20 \%$ of studies included in the aforementioned Cochrane review of the diagnostic accuracy of FRS had been published after the year 2000; most were from the 1970s, 1980s, and 1990s. ${ }^{4}$ In this newly published paper, Malinowski et al. show that FRS remain currently relevant and could be useful in psychiatric diagnosis and as practical information to predict treatment outcomes of first psychotic episode. ${ }^{5}$ The availability of biomarkers to individualize and differentiate disorders is a possible and desirable objective for the future. While such new approaches are worthwhile, psychopathology studies remain fundamentally important to the practice of clinical psychiatry.

\section{Disclosure}

The author reports no conflicts of interest.

\section{References}

1 Lavretsky $\mathrm{H}$. History of schizophrenia as a psychiatric disorder. In: Mueser KT, Jeste DV. Clinical handbook of schizophrenia. New York: Guilford; 2008. p. 3-13.

2 Kendler KS, Mishara A. The prehistory of Schneider's first-rank symptoms: texts from 1810 to 1932. Schizophr Bull. 2019;45:971-90.

3 Heinz A, Voss M, Lawrie SM, Mishara A, Bauer M, Gallinat J, et al. Shall we really say goodbye to first rank symptoms? Eur Psychiatry. 2016;37:8-13

4 Soares-Weiser K, Maayan N, Bergman H, Davenport C, Kirkham AJ, Grabowski S, et al. First rank symptoms for schizophrenia. Cochrane Database Syst Rev. 2015;1:CD010653.

5 Malinowski FR, Tasso BC, Ortiz BB, Higuchi CH, Noto C, Belangero $\mathrm{SI}$, et al. Schneider's first-rank symptoms as predictors of remission in antipsychotic-naive first-episode psychosis. Braz J Psychiatry. 2020;42:22-6.
Correspondence: Raffael Massuda, Departamento de Psiquiatria, UFPR, Rua Padre Camargo, 280, CEP 80060-240, Curitiba, PR, Brazil.

E-mail: rfmassuda@ufpr.br
How to cite this article: Massuda R. Schneider's first-rank symptoms and treatment outcome. Braz J Psychiatry. 2020;42:5. http://dx. doi.org/10.1590/1516-4446-2019-0628 